RESEARCH PAPER RP1240

Part of Journal of Research of the National Bureau of Standards, Volume 23, September 1939

\title{
DROPPING TESTS FOR MEASURING THE THICKNESS OF ZINC AND CADMIUM COATINGS ON STEEL
}

\author{
By Abner Brenner
}

\section{ABSTRACT}

The dropping test was reinvestigated because of reported difficulties with the end point. Improvements were made in the apparatus, which permitted a more constant rate of dropping of the reagent. For comparison, some thickness tests were also made by the jet, magnetic, and microscopic methods. The ammonium nitrate dropping-test reagent did not give a satisfactory end point with zincmercury coatings and did not dissolve different types of bright cadmium coatings at the same rate. A chromic acid reagent, containing $200 \mathrm{~g} / \mathrm{liter}$ of chromic acid and $50 \mathrm{~g} /$ liter of sulfuric acid, overcame these difficulties and had the additional advantage that only one reagent was required for testing different types of zinc and cadmium coatings. On commercial specimens, this reagent gave an average error of \pm 12 percent and maximum errors of about \pm 20 percent. The jet method and the microscopic method are not very satisfactory for measuring the thickness of zinc and cadmium coatings. The magnetic method usually yields errors less than +15 percent, and appears satisfactory except for thin coatings on rough basis metals.

\section{CONTENTS}

I. Introduction ..........

II. Test methods _...

1. Stripping methods

2. Dropping tests _.......... 389

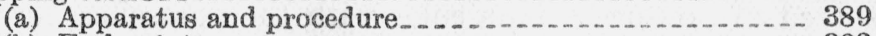

(b) End points...... 390

(c) Determination of thickness factors............. 390

3. Jet test .

4. Magnetic thickness measurements _...

5. Testing commercial articles...... 395

III. Results of tests _..................

1. Zinc coatings

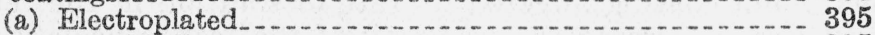

(1) Dropping tests . .

(2) Jet tests $\ldots \ldots$

(3) Magnetic measurements _...

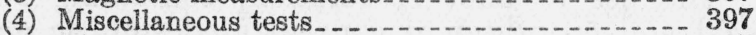

(b) Hot-dipped.......... 397

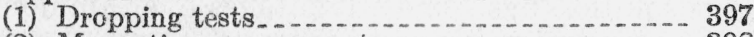

(2) Magnetic measurements $\ldots$

(c) Sherardized _... 399

(1) Dropping tests

(2) Magnetic measurements . . . . . . . . 399

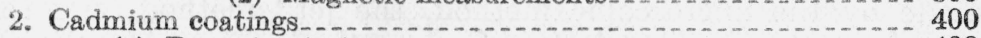

(a) Dropping tests........ 400

(b) Magnetic measurements....................... 401

3. Microscopic method for zinc and cadmium coatings . . . . . . . 401

IV. Conclusions _...

1. Dropping tests............... 401

2. Jet test_...

3. Magnetic measurements

V. Recommendations 


\section{INTRODUCTION}

The increasing adoption of specifications for the minimum thickness of plated coatings has stimulated interest in rapid methods for determining thickness. The microscopic method, which is standard, has the disadvantage of requiring expensive equipment and considerable time and does not always give satisfactory results on zinc and cadmium coatings. Often the testing of a larger number of specimens by a more rapid method would give more accurate information about an entire shipment than testing more accurately a relatively few specimens. The Preece test, in spite of its admitted shortcomings, has been "used extensively"for determining the iminimum thickness of zinc coatings. The dropping test, developed to replace the less accurate Preece test, has been incorporated in a number of commercial and Federal specifications.

The dropping test consists in dropping a corrosive solution onto a zinc or cadmium coating until the latter is penetrated. The thickness of coating is obtained by multiplying the number of seconds required for penetration by a factor previously determined for that reagent and coating. The test was devised by S. G. Clarke, ${ }^{1}$ who used a solution of iodine in potassium iodide. It was modified by Hull and Strausser, ${ }^{2}$ who substituted acidified ammonium nitrate solutions for the iodine. The test was rapidly adopted by industry, because the apparatus could be cheaply constructed from ordinary laboratory equipment, and the test could be performed by operators lacking extensive laboratory experience.

Experience with the method in general use showed that the end points were unsatisfactory for some commercial materials, especially those with coatings deposited on rough basis metals. Hull ${ }^{3}$ attempted to improve the end point by adding potassium ferricyanide to the reagent. When the coating was penetrated, enough iron was dissolved to produce a blue color with the potassium ferricyanide.

Because of the reported difficulties with the end point it was decided to study critically the dropping tests:

1. To improve the end point, if necessary by the use of a different reagent.

2. To determine whether the method of deposition of a zinc or cadmium coating affected its rate of solution in the reagent.

3 . To determine the accuracy of the test, especially when applied to commercial materials.

The use of another solution, containing $200 \mathrm{~g} /$ liter of chromic acid and $50 \mathrm{~g} /$ liter of concentrated sulfuric acid, was investigated. This solution has some advantages over ammonium nitrate solutions, as regards end point and accuracy. Both the ammonium nitrate and the chromic acid reagents were used in the following studies.

For comparison with the dropping tests, some measurements were made by the microscopic method, the jet ${ }^{4}$ method, and the magnetic $^{5}$ method. The latter two methods were developed more recently than the dropping test.

1 J. Electrodepositors' Tech. Soc. 8, Paper No. 11 (May 1933).

Monthly Rev. Am. Electroplaters' Soc. 22, 9 (March 1935); J. Research NBS 16,209 (1936) RP867.

8 Unpublished communications.

4. G. Clarke, J. Electrodepositors' Tech. Soc. 12, 1 and 157 (1936-37).

A. Brenner, J. Research NBS 20, 357 (1938) RP1081. 


\section{TEST METHODS}

\section{STRIPPING METHODS}

The average thickness of zinc or cadmium was determined by dissolving the coating from a measured area with a solution consisting of $20 \mathrm{~g}$ of antimony trioxide dissolved in 1 liter of concentrated hydrochloric acid. This reagent does not appreciably attack the steel basis metal. The average thickness of coating was calculated from the weight per unit area and the density. In general, the thickness given by the stripping method was taken as the standard with which the other results were compared. In a few cases, microscopic measurements were also made at points adjacent to those tested by other methods.

The hot-dipped and sherardized zinc coatings contain a small amount of iron which is dissolved by the stripping and dropping reagents and hence is included in the thickness of the coating. No attempt was made to determine the amount of iron in the coating.

The stripping method gives average thickness, whereas the other methods to be described give the local thickness of the coating at the points tested. To compare them with the stripping method, it is necessary that the coatings examined have a fairly uniform thickness, or that enough measurements of local thickness be made to get an average value.

\section{DROPPING TESTS}

(a) APPARATUS AND PROCEDURE

The dropping test is performed by dropping the reagent at a definite rate, that is, 100 drops per minute, onto the surface, which is inclined at an angle of about $45^{\circ}$ to the horizontal. The time required for the end point to appear is measured with a stop watch. The room temperature should be noted, as the rate of solution of the coating usually varies with temperature.

The original apparatus of Clarke consisted of a separatory funnel and two stopcocks, one of which was used to adjust the rate of dropping and the other to turn the flow of liquid on and off. It is difficult to regulate the rate of flow by a stopcock, and, after the stopcock is adjusted, the small orifice frequently clogs. In the modified apparatus (see fig. 1) this difficulty is overcome by using a capillary tube, $B$, for securing the required rate of dropping. One stopcock is provided for starting the flow. A capillary tube with a bore of approximately 0.025 in. $(0.63 \mathrm{~mm})$ and a length of $5.5 \mathrm{in} .(14 \mathrm{~cm})$ is satisfactory. Between the capillary and the stopcock of the funnel there is from 3 to 5 in. (7.5 to $12.5 \mathrm{~cm}$ ) of wide-bore tubing, to increase the head of liquid, so that the proper rate of flow is obtained. The capillary is connected to the stem of the separatory funnel by rubber tubing, in which a space of about 0.5 in. $(13 \mathrm{~mm}$ ) is left, so that the rubber tubing can be compressed when it is desired to force air bubbles or foreign matter from the glass tubes. The chromic acid reagent slowly attacks rubber tubing, and the connections must be replaced occasionally. The stopcock is lubricated with petroleum jelly, which is not attacked by chromic acid.

The volume of the drops used in these tests was about $0.05 \mathrm{ml}$. To obtain drops of this size, the end of the capillary was tapered for 
about $0.5 \mathrm{in.}(1 \mathrm{~cm})$ to a tip which had an outside diameter of about 0.14 in. $(3.3 \mathrm{~mm})$. The glass tube, $A$, inside the funnel serves to maintain a constant head of liquid. By moving this tube up or down, small adjustments can be made in the rate of dropping. There was no difficulty in keeping the rate of dropping at $100 \pm 3$ drops per minute.

When tests were made with ammonium nitrate reagents, the tip of the capillary was placed about 0.4 in. $(1 \mathrm{~cm})$ above the surface of the specimen. With the chromic acid reagent, the distance was increased to about $0.8 \mathrm{in} .(2.0 \mathrm{~cm})$, because at the shorter distance a drop would occasionally bounce off the metal without spreading. A variation of 20 percent in these distances did not appreciably affect the accuracy of the test.

The apparatus shown in figure 1 has a pivoted rod, $C$, which can be turned down to gage the distance from the capillary tip to the metal and then swung up out of the way. The test specimen was inclined at $45^{\circ}$ to the horizontal. Although the angle is not critical (a variation of $\pm 15^{\circ}$ produces an error of \pm 10 percent), it should not vary too much from $45^{\circ}$ if satisfactory results are desired. The spent solution should drain freely from the specimen. When tests are made near an edge, it is advisable to place a strip of cloth on the edge to act as a wick for drawing off the spent solution. The specimens should be solvent-degreased, then scrubbed with magnesium oxide paste, rinsed, and dried. The specimen and apparatus must be rigidly fixed during the test, so that successive drops strike the same spot.

\section{(b) END POINTS}

The end point of the test is the exposure of the basis metal, which usually offers enough contrast of color to be readily distinguished from the surrounding area of etched coating. The exposure of smooth basis metal occurs rather suddenly, and the area rapidly increases as more reagent is added. On rough basis metal, especially on cast iron, the end point is not sharp, and the basis metal may be revealed through a few minute areas before the general breakdown. In such case, the end point was taken when small areas of basis metal had appeared over a total area about $1 / 8$ in. $(3 \mathrm{~mm}$ ) in diameter, although these areas of bare iron were irregularly distributed and were intermingled with areas of incompletely dissolved coating. The test would have to be run about 10 to 20 percent longer to produce a continuous area of bare metal.

\section{(c) DETERMINATION OF THICINESS FACTORS}

The compositions of the dropping test reagents and their "thickness factore" are given in table 1. The thickness factors for each reagent were determined by dividing the known thickness of coating (in hundred-thousandths of an inch) by the number of seconds required for penetration. The thickness of any zinc or cadmium coating, in hundred-thousandths of an inch, is obtained by multiplying the number of seconds required for penetration by the appropriate factor. Hull and Strausser attempted to prepare reagents of such concentrations that the factors would be unity, that is, each second of test would correspond to $0.00001 \mathrm{in}$. $(0.00025 \mathrm{~mm})$ of coating. However, as the rates of attack of several of the solutions have considerable 


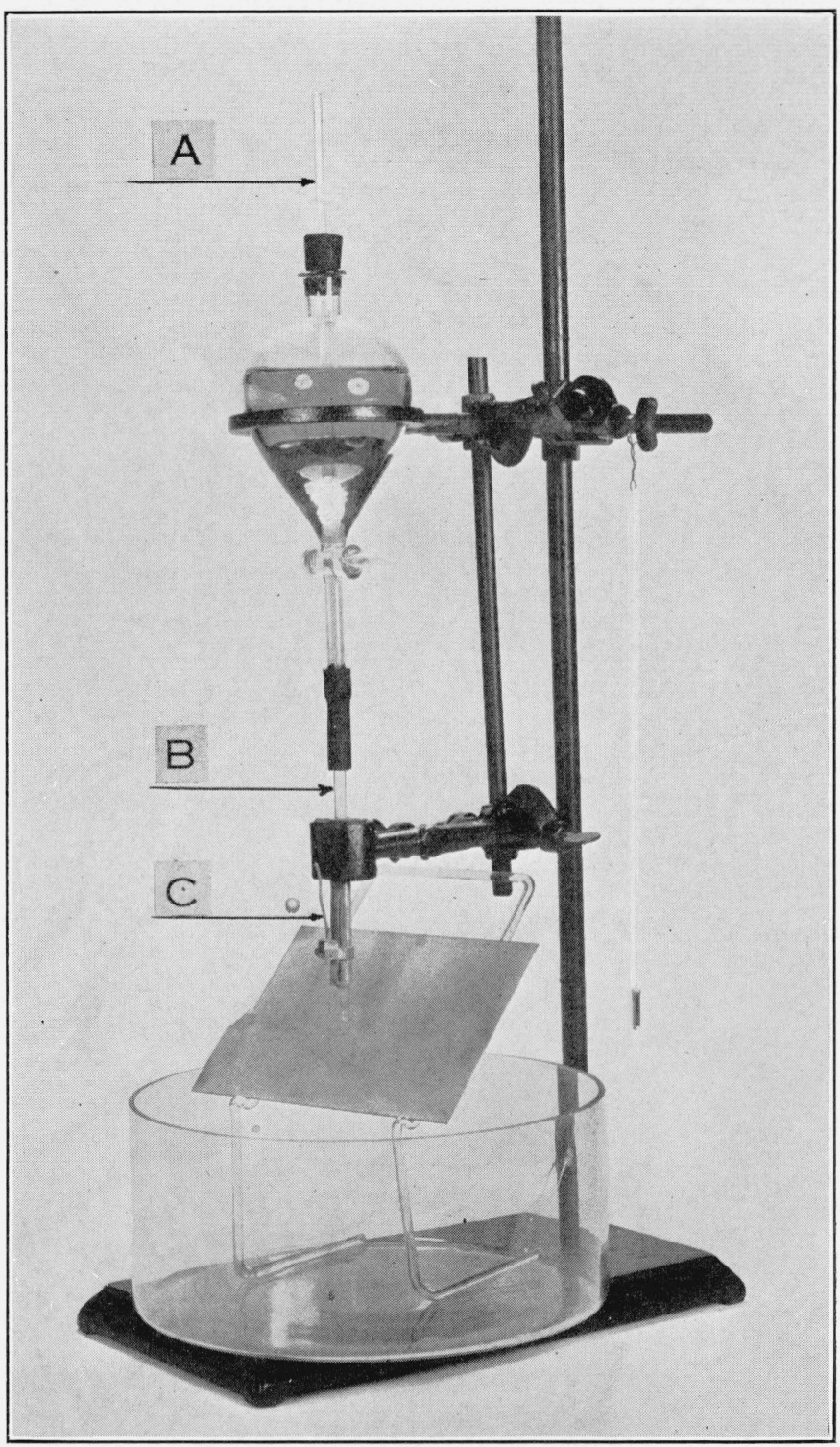

FiguRE 1.-Dropping-test apparatus.

$A$, Glass tube for maintaining a constant head of liquid; $B$, capillary tube; and $C$, device for adjusting the distance between the capillary tip and the specimen. 
temperature coefficients, the unity factor applies to only one temperature. In the work here reported no attempt was made to devise solutions with a factor of unity at any given temperature. Instead convenient solutions were used and factors were determined for the customary temperature range.

TABLE 1.-Composition and thickness factors of test solutions

\begin{tabular}{|c|c|c|c|c|c|c|c|c|}
\hline \multirow{3}{*}{$\begin{array}{l}\text { Reagent } \\
\text { symbol a }\end{array}$} & \multirow{3}{*}{ Coating to be tested } & \multicolumn{5}{|c|}{ Composition of reagent } & \multirow{2}{*}{\multicolumn{2}{|c|}{$\begin{array}{l}\text { Thickness fac- } \\
\text { tors (hundred } \\
\text { thousandth } \\
\text { of an inch per } \\
\text { second) }\end{array}$}} \\
\hline & & \multicolumn{2}{|c|}{ Oxidizing agent } & \multicolumn{3}{|c|}{ Acid } & & \\
\hline & & Formula & g/liter & Formula & $\begin{array}{c}\text { ml/liter } \\
\text { (conc.) }\end{array}$ & $\begin{array}{l}\text { Normality } \\
\text { in reagent }\end{array}$ & $\begin{array}{c}70^{\circ} \mathrm{F} \\
\left(21^{\circ} \mathrm{C}\right)\end{array}$ & $\begin{array}{l}95^{\circ} \mathrm{F} \\
\left(35^{\circ} \mathrm{C}\right)\end{array}$ \\
\hline $\begin{array}{l}N_{B} \ldots \ldots \\
N_{H} \\
N_{B} \ldots \ldots \\
N_{\mathrm{Cd}} \ldots \ldots\end{array}$ & $\begin{array}{l}\text { Electroplated zinc } \\
\text { Hot-dipped zinc } \\
\text { Sherardized zinc } \\
\text { Electroplated cadmium }\end{array}$ & $\begin{array}{l}\mathrm{NH}_{4} \mathrm{NO}_{3--} \\
\mathrm{NH}_{4} \mathrm{NO}_{3--} \\
\mathrm{NH}_{4} \mathrm{NO}_{3--} \\
\mathrm{NH}_{4} \mathrm{NO}_{3--}\end{array}$ & $\begin{array}{l}g \\
100 \\
100 \\
100 \\
110\end{array}$ & $\begin{array}{l}\mathrm{HNO}_{3} . . \\
\mathrm{HCl} \\
\mathrm{HCl} \\
\mathrm{HCl} \\
\mathrm{HCl}\end{array}$ & $\begin{array}{r}m l \\
55 \\
75 \\
125 \\
10\end{array}$ & $\begin{array}{l}0.85 \\
.85 \\
1.45 \\
0.12\end{array}$ & $\begin{array}{l}1.03 \\
0.93 \\
1.24 \\
0.95\end{array}$ & $\begin{array}{l}\text { 1. } 06 \\
1.01 \\
1.64 \\
1.30\end{array}$ \\
\hline $\begin{array}{l}\mathrm{CrO}_{3}-\mathrm{Zn} \\
\mathrm{CrO}_{3}-\mathrm{Zn}_{--} \\
\mathrm{CrO}_{3}-\mathrm{Zn}_{-}\end{array}$ & $\begin{array}{l}\text { Electroplated zinc } \\
\text { Hot-dipped zinc. } \\
\text { Sherardized zinc. }\end{array}$ & $\begin{array}{l}\mathrm{CrO}_{3} \\
\mathrm{CrO}_{3} \\
\mathrm{CrO}_{3}\end{array}$ & $\begin{array}{l}200 \\
200 \\
200\end{array}$ & $\begin{array}{l}\mathrm{H}_{2} \mathrm{SO}_{4}-- \\
\mathrm{H}_{2} \mathrm{SO}_{4-\ldots} \\
\mathrm{H}_{2} \mathrm{SO}_{4-\ldots}\end{array}$ & $\begin{array}{l}50 \\
50 \\
50\end{array}$ & $\begin{array}{l}3.0 \\
3.0 \\
3.0\end{array}$ & $\begin{array}{r}.97 \\
1.01 \\
.96\end{array}$ & $\begin{array}{l}\text { 1. } 19 \\
\text { 1. } 21 \\
\text { 1. } 21\end{array}$ \\
\hline $\mathrm{CrO}_{3} \cdot \mathrm{Cd}$ & $\begin{array}{l}\text { Electroplated cadmium } \\
\text { Electroplated zinc................ }\end{array}$ & $\begin{array}{l}\mathrm{CrO}_{3} \\
\mathrm{NH}_{4} \mathrm{NO}_{3-}\end{array}$ & $\begin{array}{r}200 \\
70\end{array}$ & $\begin{array}{l}\mathrm{H}_{2} \mathrm{SO}_{4} \ldots \\
\mathrm{HCl}\end{array}$ & $\begin{array}{r}50 \\
\times 70\end{array}$ & $\begin{array}{l}\text { Average } d \\
\\
3.0 \\
0.07\end{array}$ & $\begin{array}{l}\text { 1. } 33 \\
2.25\end{array}$ & $\begin{array}{l}1.60 \\
3.15\end{array}$ \\
\hline
\end{tabular}

a Solutions $N_{B}, N_{H}$, and $N_{C d}$ were developed by Hull and Strausser. Solution $N_{B}$ was developed by W. G. Schlecht of this laboratory. Solution $J$ was recommended by Clarke for the jet test.

$\checkmark$ Jet test.

c 1.0 Normal acid.

$\checkmark$ Average of the thickness factors of the chromic acid reagent for zinc coatings.

The factors in table 1 were determined at $70^{\circ} \mathrm{F}\left(21^{\circ} \mathrm{C}\right)$ and $95^{\circ} \mathrm{F}$ $\left(35^{\circ} \mathrm{C}\right)$, and the factors for intermediate temperatures were obtained by linear interpolation between the two points (fig. 2). The factors are not necessarily linear functions of temperature, but the accuracy of the test is not sufficient to determine the shape of the curve over this short range.

The factors for electrodeposited zinc and cadmium, tables 2 and 3 , are average values obtained partly by testing flat specimens which had been plated from typical solutions at the National Bureau of Standards under conditions giving coatings of known and uniform thickness. In addition, dropping tests were made on some coatings plated by several commercial firms on smooth steel, using proprietary bright plating baths as well as the ordinary acid and cyanide baths.

Each value in tables 2 and 3 is the average of three or more dropping tests, which had a reproducibility of about \pm 6 percent.

From table 1 it may be seen that the average factor for zinc for the $N_{E}$ solution (previously recommended) is close to unity and has only a small temperature coefficient, which confirms the work of Hull and Strausser. Table 2 shows that the average deviation of the factor from the mean for different electroplated zinc coatings was \pm 6 percent 
and that the maximum deviation was \pm 13 percent. These deviations are within the limits of accuracy given by Hull and Strausser for the test. With the chromic acid reagent the factors for the different zinc coatings showed less variation than with the ammonium nitrate reagent.

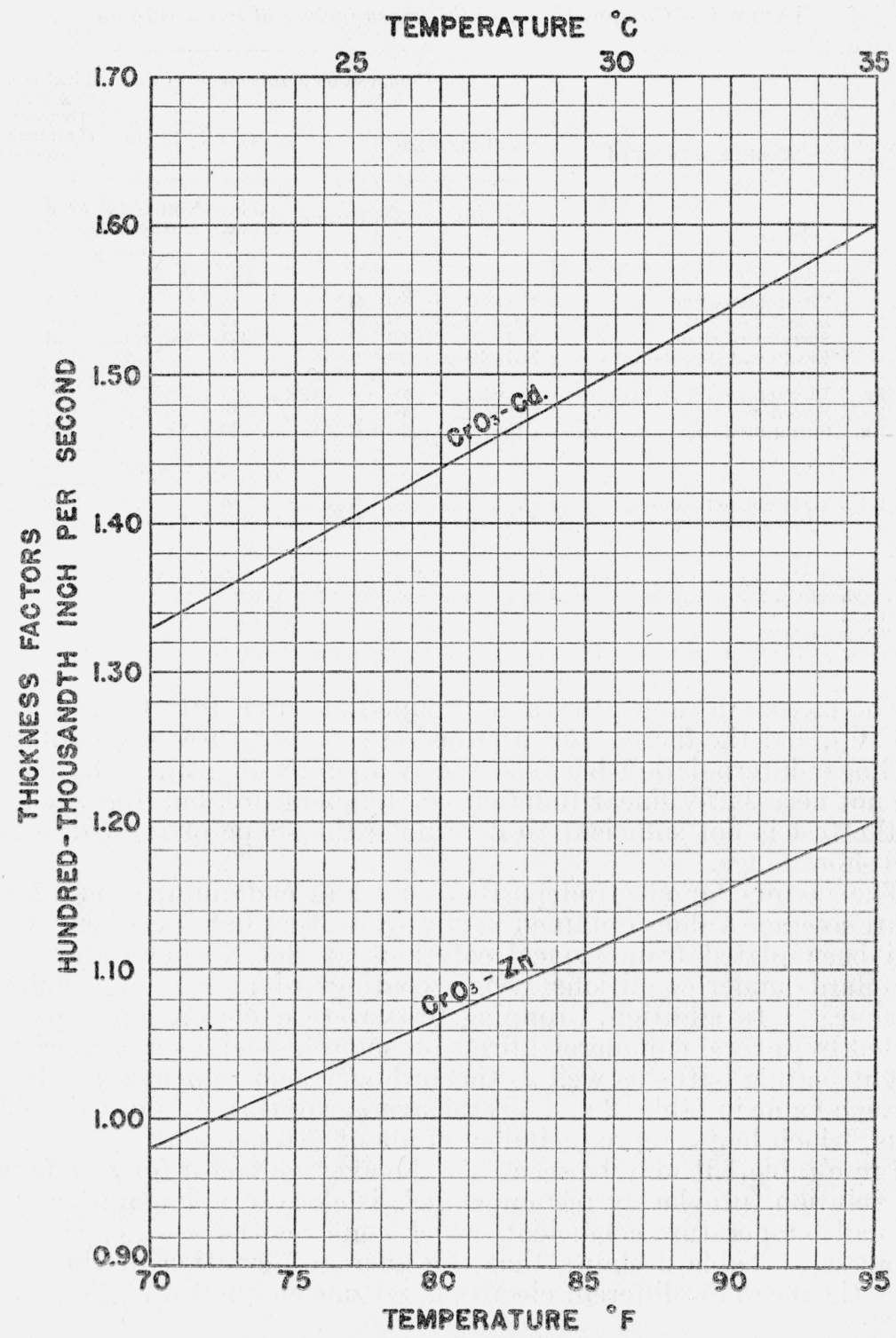

FIGURE 2.-Thickness factors for the $\mathrm{CrO}_{3}$ dropping-test reagents. 
TABLE 2.-Thickness factors for zinc coatings

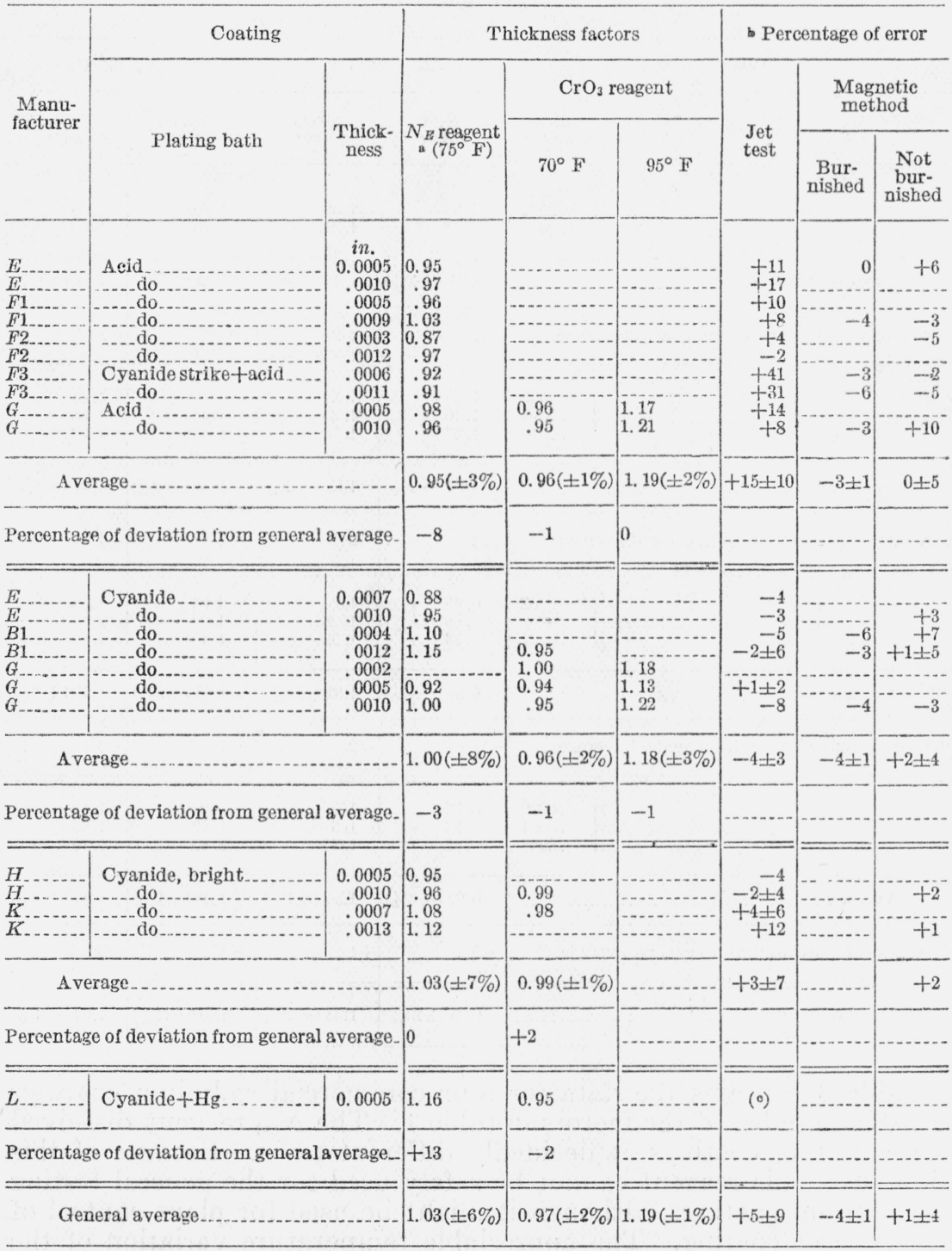

- Since the factor varies little with temperature, most of the tests were made at only one temperature.

- Based on stripping test.

- Unsatisfactory end point. 
TABLE 3.-Thickness factors for the dropping test on electroplated cadmium coatings

\begin{tabular}{|c|c|c|c|c|c|}
\hline \multicolumn{2}{|c|}{ Coating } & \multicolumn{2}{|c|}{$70^{\circ} \mathrm{F}\left(21^{\circ} \mathrm{C}\right)$} & \multicolumn{2}{|c|}{$95^{\circ} \mathrm{F}\left(35^{\circ} \mathrm{C}\right)$} \\
\hline Manufacturer & $\begin{array}{l}\text { Thick. } \\
\text { ness }\end{array}$ & $\begin{array}{c}\mathrm{Ncd} \\
\text { factor }\end{array}$ & $\begin{array}{l}\mathrm{CrO}_{3} \\
\text { factor }\end{array}$ & $\begin{array}{l}\mathrm{Ncd} \\
\text { factor }\end{array}$ & $\begin{array}{l}\mathrm{CrO}_{3} \\
\text { factor }\end{array}$ \\
\hline A........ & $\left\{\begin{array}{l}\text { in } \\
0.0002 \\
.0005\end{array}\right.$ & $\begin{array}{l}1.08 \\
1.14\end{array}$ & $\begin{array}{l}1.40 \\
1.31\end{array}$ & $\begin{array}{l}1.36 \\
1.50\end{array}$ & $\begin{array}{l}1.60 \\
1.62\end{array}$ \\
\hline \multicolumn{2}{|c|}{ Average } & $1.11( \pm 3 \%)$ & $1.35( \pm 4 \%)$ & $1.43(5 \pm \%)$ & $1.61( \pm 1 \%)$ \\
\hline \multicolumn{2}{|c|}{ Percentage of deviation from general average..... } & +17 & +2 & +10 & +1 \\
\hline \multirow{2}{*}{\multicolumn{2}{|c|}{$B \ldots+\left\{\begin{array}{l}.0002 \\
.0004 \\
.0010\end{array}\right.$}} & $\begin{array}{l}1.06 \\
1.10 \\
1.07\end{array}$ & $\begin{array}{l}\text { 1. } 29 \\
\text { 1. } 35 \\
1.30\end{array}$ & $\begin{array}{l}1.50 \\
1.45 \\
1.44\end{array}$ & $\begin{array}{l}\text { 1. } 60 \\
1.58 \\
1.60\end{array}$ \\
\hline & & $1.08( \pm 2 \%)$ & $1.31( \pm 2 \%)$ & $1.46( \pm 2 \%)$ & $1.59( \pm 1 \%)$ \\
\hline \multicolumn{2}{|c|}{ Percentage of deviation from general average...... } & +14 & -2 & +12 & -1 \\
\hline \multirow{2}{*}{\multicolumn{2}{|c|}{$C \ldots 002\left\{\begin{array}{l}.0002 \\
.0005 \\
.0007\end{array}\right.$}} & $\begin{array}{r}0.68 \\
.66 \\
.73\end{array}$ & $\begin{array}{l}1.34 \\
1.28 \\
1.32\end{array}$ & $\begin{array}{l}0.93 \\
1.00 \\
1.16\end{array}$ & $\begin{array}{l}\text { 1. } 53 \\
1.54 \\
1.59\end{array}$ \\
\hline & & $0.69( \pm 4 \%)$ & $1.31( \pm 2 \%)$ & $1.03( \pm 9 \%)$ & $1.55( \pm 1 \%)$ \\
\hline \multicolumn{2}{|c|}{ Percentage of deviation from general average..... } & -27 & -2 & -21 & -3 \\
\hline \multirow{2}{*}{\multicolumn{2}{|c|}{$D \ldots\left(\begin{array}{l}.0002 \\
.0004 \\
.0007\end{array}\right.$}} & $\begin{array}{r}0.92 \\
.96 \\
.87\end{array}$ & $\begin{array}{l}\text { 1. } 35 \\
1.31 \\
1.35\end{array}$ & $\begin{array}{l}1.27 \\
1.29 \\
1.30\end{array}$ & $\begin{array}{l}1.53 \\
1.66 \\
1.70\end{array}$ \\
\hline & & $0.92( \pm 3 \%)$ & $1.34( \pm 1 \%)$ & $1.29( \pm 1 \%)$ & $1.63( \pm 4 \%)$ \\
\hline \multicolumn{2}{|c|}{ Percentage of deviation from general average } & -3 & +1 & -1 & +5 \\
\hline General average... & & $0.95( \pm 15 \%)$ & $1.33( \pm 2 \%)$ & $1.30( \pm 11 \%)$ & $1.60( \pm 3 \%)$ \\
\hline
\end{tabular}

Table 3 contains the data for four commercial cadmium coatings on which are based the factors in table 1 . The $N_{\mathrm{Cd}}$ reagent dissolved the cadmium coatings at decidedly different rates. Because of this difference, this reagent cannot be safely used for the general testing of cadmium coatings, although it might be used for plant control of one type of coating. The appreciable temperature variation of the factor for the $N_{\mathrm{Cd}}$ reagent (over 1 percent per degree Fahrenheit) was not previously reported. The chromic acid reagent gave about the same factor with all four coatings and the temperature coefficient of the factor is about 1 percent per degree Fahrenheit.

The factors in table 1 for hot-dipped and sherardized coatings were obtained by testing commercial coatings. The results will be discussed in more detail in a later section. The chromic acid reagent has the same factor $\left(0.98\right.$ at $\left.70^{\circ} \mathrm{F}\right)$ within a few percent for electroplated, hot-dipped, and sherardized zinc, and hence only one factor need be used. 


\section{JET TEST}

The jet test differs from the dropping test in that the reagent strikes the surface in a continuous stream instead of in drops. The dimensions of the jet tube and the head of liquid must meet certain specifications, as defined by Clarke. The apparatus, procedure, and thickness factors used in these tests were in accordance with Clarke's recommendations.

\section{MAGNETIC THICKNESS MEASUREMENTS}

The thickness of coatings was measured also by a magnetic method, which can be used for any nonmagnetic coating on steel. The method depends on the decrease in the attractive force between a permanent magnet and the steel basis metal when the two are separated by a coating. The instrument, called a "Magne-gage," is calibrated with standard samples having a known thickness of coating plated on steel.

\section{TESTING COMMERCIAL ARTICLES}

The commercial articles to which the various tests were applied consisted mainly of electrical accessories, such as conduit boxes, utility boxes, and condulets, which were donated by a number of firms. The basis metals consisted of mild sheet steel, malleable iron, and gray cast iron, all of the surfaces of which were usually rough. The coatings included electroplated, hot-dipped, and sherardized zinc, and electroplated cadmium. These articles are representative of commercial products which might be subjected to a dropping test.

The accuracy of the dropping tests on commercial materials was determined by comparison with the antimony trichloride stripping method, which was taken as the standard. The specimens for the stripping test usually had an area of 6 to $20 \mathrm{~cm}^{2}$ (1 to 3 in. $\left.{ }^{2}\right)$ and were cut from the center of the sample, where the coating was more likely to be of uniform thickness than near an edge. The test piece was weighed, one side protected with a "stop-off" lacquer, and the other side tested with the Magne-gage and then with two to four dropping tests. The remainder of the coating was dissolved in the antimony trichloride reagent, the lacquer removed, and the loss in weight determined. From the loss in weight, the average thickness was calculated and compared with the results of the other tests. The thickness of the coating did not appreciably affect the accuracy of the dropping test, provided that the coating was at least several tenthousandths of an inch thick. On thinner coatings the accuracy was less, because each second of error in time produced a relatively large percentage of error in thickness.

\section{RESULTS OF TESTS}

\section{ZINC COATINGS}

(a) ELECTROPLATED

(1) Dropping tests.- The results of tests on commercial zinc-plated articles are given in table 4. As the basis metals of these articles were rough, the dropping-test end points were not as sharp as those 
obtained on smooth steel. The end points given by the Hull-Strausser reagent, $N_{E}$, were usually satisfactory on all electrodeposited zinc coatings except those containing mercury. ${ }^{6}$ The end points on these coatings were either indistinct or undetectable because the etched zinc coating and the steel had about the same gray color.

The modified reagent suggested by Hull (reagent $N_{E^{\prime}}$ ) was tried on several coatings. The end point consists in the appearance of a blue color. On ordinary zinc coatings, the modified reagent gave results of about the same degree of accuracy as the $N_{E}$ reagent. On zincmercury coatings, however, the results were 10 to 20 percent high for coatings more than 0.0005 in. thick and more than 20 percent high for thinner coatings. Apparently the mercury deposited on the steel and retarded the attack necessary for the formation of the blue color.

TABLE 4.--Accuracy of thickness measurements of commercial electroplated zinc coatings

\begin{tabular}{|c|c|c|c|c|c|c|c|c|c|}
\hline \multirow{3}{*}{$\begin{array}{l}\text { Manu- } \\
\text { lacturers }\end{array}$} & \multirow{3}{*}{ Basis metal } & \multicolumn{2}{|c|}{ Coating } & \multicolumn{6}{|c|}{ Percentage of error d } \\
\hline & & \multirow[b]{2}{*}{ Type } & \multirow[b]{2}{*}{$\begin{array}{l}\text { Thick- } \\
\text { ness }\end{array}$} & \multicolumn{3}{|c|}{ Dropping-test solutions } & \multirow{2}{*}{$\begin{array}{c}\text { Jet so- } \\
\text { lution }\end{array}$} & \multicolumn{2}{|c|}{ Magne-gage } \\
\hline & & & & $N_{B}$ & $* N^{\prime}$ & $\mathrm{CrO}_{3}$ & & $\begin{array}{l}\text { Burn- } \\
\text { ished }\end{array}$ & $\begin{array}{l}\text { Not } \\
\text { burn- } \\
\text { ished }\end{array}$ \\
\hline$M_{-}$ & Sheet steel. . & Ordinary.. & $\left\{\begin{array}{c}\text { in. } \\
0.0004 \\
.0018 \\
0002\end{array}\right.$ & $\begin{array}{l}-12 \\
-12\end{array}$ & $0 \pm 4$ & $\begin{array}{r}-7 \\
-18\end{array}$ & +5 & +10 & +25 \\
\hline & $\int \ldots$ do & -..do & $\left\{\begin{array}{l}.0004 \\
.0008\end{array}\right.$ & -11 & & -7 & \pm 9 & 13 & $\begin{array}{r}T 14 \\
\ldots .+2\end{array}$ \\
\hline$N_{-}$ & Cast iron.... & .... do... & $\left\{\begin{array}{l}.0010 \\
.0017\end{array}\right.$ & -11 & & +7 & & -12 & -10 \\
\hline$P_{\ldots-}$ & Sheet steel.. & ...do do & $\left\{\begin{array}{l}.0005 \\
.0007\end{array}\right.$ & -13 & & -18 & & -12 & -3 \\
\hline Q... & Steel tubing.... & ....do do... & $\left\{\begin{array}{l}.0009 \\
.0012\end{array}\right.$ & -9 & -5 & -5 & & & \\
\hline$R_{-.}$ & Malleable iron. & ...do_... & $\left\{\begin{array}{l}.0005 \\
.0008 \\
.0004 \\
.0005\end{array}\right.$ & $\left\{\begin{array}{l}-14 \\
+36\end{array}\right.$ & & $\begin{array}{l}-14 \\
+1 \pm 10\end{array}$ & (b) & -18 & +3 \\
\hline$S_{\ldots}$ & Sheet steel. & $\mathrm{Zn}-\mathrm{Hg}$ & $\left\{\begin{array}{l}.0006 \\
.0012 \\
.0002 \\
.0003\end{array}\right.$ & $\left\{\begin{array}{l}0-7 \\
0+6 \pm 16\end{array}\right.$ & $\begin{array}{r}0 \pm 10 \\
+75\end{array}$ & $\begin{array}{l}-8 \\
+2 \pm 13\end{array}$ & & & 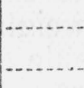 \\
\hline$T$ & ...... do . & ... do & $\left\{\begin{array}{l}.0002 \\
.0004\end{array}\right.$ & +12 & +70 & $+3 \pm 6$ & (b) & & \\
\hline$U_{\ldots}$ & ...... do & ... do & $\left\{\begin{array}{r}.0006 \\
.0009 \\
\end{array}\right.$ & +60 & +23 & +7 & (b) & -7 & +5 \\
\hline Ave & age... & & -........... & $+2 \pm 18$ & $+22 \pm 29$ & $-6 \pm 8$ & 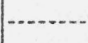 & $-4 \pm 11$ & $+6 \pm 9$ \\
\hline
\end{tabular}

* The $N^{\prime} B$ solution was the $N_{B}$ solution to which $3.0 \mathrm{~g} /$ liter of potassium ferricyanide had beeen added - Reagent dissolved the coating too slowly to permit definite readings.

- The $N_{B}^{\prime}$ solution was used, but the ordinary end point was observed instead of the appearance of the blue color.

d When averages are expressed in the form $A \pm B, A$ represents the systematic difference of the measurements from the correct value, and $B$ represents the precision of $A$.

The chromic acid reagent gave satisfactory end points on all electroplated zinc coatings tested, including zinc-mercury deposits. On ordinary zinc coatings the end point was made visible by contrast of the white steel with the yellow color acquired by zinc. On zincmercury coatings, a black color suddenly appeared just before the

\footnotetext{
- The zinc-mercury coatings, deposited from a cyanide bath, may contain up to several percent of mercury.
} 
steel was exposed. Usually a few more drops of reagent dissolved this black layer and revealed the dull gray steel.

(2) Jet tests.- Only a small number of measurements were made with the jet test, as it does not offer any advantage over the dropping test for zinc coatings and possesses the following disadvantages:

1. The reagent recommended by Clarke dissolves zinc-mercury coatings at a much slower and less definite rate than other zinc coatings.

2. The end point is difficult to see because the initial penetration of the coating occurs only over a tiny crescent-shaped area. In many cases a hand lens is necessary to detect the end point. This difficulty is increased when the basis metal is rough.

3 . As the end point cannot be seen while the test is in progress, the flow of liquid must be stopped at intervals so that the surface can be examined for the end point.

(3) Magnetic measurements.- Tests performed with the Magne-gage involve no end point. Since the surfaces of the materials were rough, it was necessary to take the average of a number of readings. Practically all the errors were less than \pm 15 percent. Because of the usual roughness of such surfaces, measurements cannot be made on cast iron with this degree of accuracy, unless the coatings are at least 0.0008 in. thick. Measurements with the Magne-gage were also made on the test specimens after burnishing a small area with a half-inch steel ball. This somewhat increased the reproducibility of the readings but tended to make the measurements low. Apparently the burnishing is advantageous if the basis metal is mild steel, but it does not help much if the metal is cast iron.

(4) Miscellaneous tests. - A few of the commercial coatings consisted of a layer of cadmium covered by a coating of zinc. These coatings cannot be tested by the dropping method because zinc and cadmium have different rates of solution. The average thickness of each layer can be ascertained by boiling the specimen in a solution of sodium hydroxide, which dissolves the zine without attacking the cadmium undercoating. The cadmium can then be dissolved with ammonium nitrate solution.

A simple qualitative test for the presence of mercury in a zinc coating is as follows: Dilute nitric acid $(1: 4)$ is poured on to the surface, which is then rubbed with a piece of clean copper foil. If mercury is present a silvery stain will appear on the copper. The usual procedure of testing a coating by first dissolving it in acid is not successful with zinc-mercury coatings, because the mercury remains on the iron surface and no test for mercury is then obtained in the solution.

\section{(b) HOT-DIPPED}

(1) Dropping tests.-The factors for the Hull-Strausser dropping test reagent, $N_{H}$, and the chromic acid reagent were obtained by testing galvanized sheet from six different sources, with coatings from 0.001 to 0.0015 in. in thickness. The average values of the factors are given in table 1. The factor for the $N_{H}$ solution is fairly close to unity, which is the value given by Hull and Strausser. For both reagents, the average deviation of the factor from the mean was \pm 4 percent and the maximum \pm 10 percent. This shows that there was no important difference in the behavior of the coatings from different sources. 
The end points of both reagents were satisfactory on the galvanized sheet. With the $N_{H}$ reagent, the zinc turned black, and at the end point the steel appeared white against the black zinc. The chromic acid reagent also gradually turned the zinc black, but just before the end point the black color gave way to a light gray layer, which was quickly penetrated and revealed the bright steel basis metal.

Table 5 gives the results of some additional tests on hot galvanized electrical fittings. There was no difficulty in obtaining fairly accurate results for coatings on mild steel sheet, as the end point was easily seen. However, the end points of coatings on cast iron were not satisfactory, as the iron had a black color which did not offer a contrast with the black color acquired by the zinc. The $N_{H}$ reagent gave no evident end point, but apparently when the cast iron was exposed, the zinc began to dissolve with effervescence. This point of effervescence was taken as an approximate end point, but it was not satisfactory. The end point given by the chromic acid reagent did not show sufficient contrast to be seen through the colored reagent. In order to see the end point, the flow of reagent had to be stopped and the solution rinsed from the surface with several drops of water. The end point consisted of a black area of cast iron showing through gray zinc. Whenever there was any doubt of an end point being reached (with either reagent), the surface was tested with a few drops of copper sulfate solution. Bright copper coated any exposed iron, but only a black mossy deposit formed on the zinc surface.

TABLE 5.-Accuracy of thickness measurements of commercial hot-dipped zinc coatings

\begin{tabular}{|c|c|c|c|c|c|}
\hline \multirow{3}{*}{$\begin{array}{l}\text { Manufac- } \\
\text { turer }\end{array}$} & \multirow{3}{*}{ Basis metal } & \multirow{3}{*}{$\begin{array}{l}\text { Coating } \\
\text { thickness }\end{array}$} & \multicolumn{3}{|c|}{ Percentage of error } \\
\hline & & & \multicolumn{2}{|c|}{ Dropping tests } & \multirow{2}{*}{$\begin{array}{l}\text { Magne. } \\
\text { gage }\end{array}$} \\
\hline & & & $\begin{array}{l}\text { Solution } \\
N_{H}\end{array}$ & $\begin{array}{l}\text { Solution } \\
\mathrm{CrO}_{3}\end{array}$ & \\
\hline$W_{-\cdots}$ & $\begin{array}{l}\text { Mild steel } \\
\text { Steel tubing }\end{array}$ & $\begin{array}{l}\text { in. } \\
0.0030 \\
.0016\end{array}$ & $\begin{array}{l}-4 \\
-7\end{array}$ & $\begin{array}{l} \pm 2 \\
-4\end{array}$ & $\begin{array}{l} \pm 5 \\
-7\end{array}$ \\
\hline \multirow{3}{*}{$\begin{array}{l}X \\
Y \\
Z\end{array}$} & \multirow{3}{*}{$\begin{array}{l}\text { Malleable iron } \\
\text { Cast iron }\end{array}$} & Average... & -6 & \pm 3 & \pm 6 \\
\hline & & $\begin{array}{l}.0045 \\
.0035 \\
.0030\end{array}$ & $\begin{array}{l}-8 \\
-24 \\
-25\end{array}$ & $\begin{array}{l}-18 \\
-18 \\
+4\end{array}$ & $\begin{array}{l}-5 \\
-13 \\
-12\end{array}$ \\
\hline & & Average ... & -19 & $-11 \pm 10$ & -10 \\
\hline
\end{tabular}

(2) Magnetic measurements.- Tests were made with the Magne-gage on the six specimens of galvanized sheet which had been used for standardizing the drop-test reagents (table 1). The average error was -7 percent and the maximum error -11 percent. The measurements on galvanized fittings, recorded in table 5 , are also about 10 percent low. These results check previous magnetic measurements on hotdipped coatings which showed a systematic error of -10 percent, probably caused by the alloying of the iron and zinc. This error can be eliminated by the use of a correction factor or by standardizing the instrument against hot-dipped zinc coatings of known thickness. 
(c) SHERARDIZED

(1) Dropping tests. - The thickness factors (table 1) for the $N_{s}$ and chromic acid reagents were obtained by testing commercial sherardized coatings from three different sources. The coatings were between 0.001 and 0.003 in. thick and had been applied to mild steel. For each reagent, the average deviation of the measurements from the mean was about \pm 7 percent, and the maximum deviation about \pm 18 percent. As no additional sherardized samples from other sources were available, the accuracy of the dropping tests could not be determined in general, but from the above results the method is probably reliable within about \pm 15 percent.

The end points for sherardized coatings on mild steel appeared rather gradually and were not as distinct as those for hot-dipped coatings. Since the coatings were thick, this did not cause a serious percentage error. The $N_{s}$ reagent turned the surface dark, and the end point consisted in the exposure of the white steel. The appearance of the area during the test varied with the specimen and thickness of coating. Some coatings yielded alternate black and silvery layers, and the occurrence of the latter might be mistaken for the steel. In cases of doubt, the test was stopped ${ }^{7}$ for a few seconds, whereupon any silver-colored zinc layer immediately turned black, whereas exposed steel darkened but slightly. The chromic acid reagent gave an end point similar to its end point on hot-dipped coatings. The sherardized surface turned dark brown, and the end point occurred when the silvery colored steel appeared. Sometimes, shortly before the end point, the brown color was succeeded by a yellow layer, which was rapidly penetrated to expose the steel.

The end points of the dropping test for sherardized coatings on cast iron are similar to the end points for hot-dipped coatings on cast iron and are not very satisfactory. Hence, the accuracy of the method on this material was not determined.

When dropping tests are to be made on hot-dipped or sherardized coatings, one should make a preliminary test in order to become familiar with the sequence of color changes and not mistake one of them for the end point. The preliminary test should be allowed to proceed long enough to make certain that the steel has been exposed.

To determine the ease of recognizing the end points for hot-dipped and sherardized coatings on mild steel, three different observers performed dropping tests after reading the written instructions. The average error of the tests on galvanized sheet was \pm 5 percent for both reagents. On the sherardized coatings, the average error was \pm 8 percent for the chromic acid reagent and \pm 16 percent for the $N_{s}$ reagent.

(2) Magnetic measurements.-When measurements were made on sherardized coatings with the Magne-gage, it was necessary to burnish the area tested, as the coatings were rough. The thicknesses given by the Magne-gage were somewhat high as compared with the thickness calculated from the stripping method. The average error was +8 percent and the maximum error +16 percent. If the surface was not burnished, the errors were about twice as large. The stripping method, using 7.1 for the density of zinc, has been taken as the

\footnotetext{
"The time for tests which were interrupted was measured with a "stop and go" type of stop watch.
} 
standard measure of thickness. However, the sherardized coatings may be thicker than corresponds to the weight of coatings and density of zinc, because they are somewhat porous and may contain oxide.

\section{CADMIUM COATINGS}

\section{(a) DROPPING TESTS}

Table 6 gives the results of tests made on cadmium-coated materials obtained from seven different manufacturers. The $N_{\mathrm{Cd}}$ and chromic acid reagents gave sharp end points with cadmium coatings plated on mild steel, especially if the basis metal was smooth. However, the end point for cadmium on rough cast iron surfaces was less satisfactory. With the $N_{\text {Ca }}$ reagent, some of the cadmium coatings on cast iron turned dark gray or black, apparently because they contained some impurity, and as the steel was also dark in color, the end point could be distinguished with difficulty, if at all. In these cases, addition of potassium ferricyanide to the $N_{\mathrm{Cd}}$ reagent did not improve the accuracy of the test, as apparently the blue color did not appear until the end point was passed. The chromic acid reagent gave a visible end point on all the cadmium-plated cast iron tested. During the test, the cadmium became bright and, at the end point, contrasted with the dull-colored iron. The end point was most easily observed by viewing at the angle which best showed the difference in the reflecting power of the metals.

TABLE 6.-Accuracy of thickness measurements of commercial electroplated cadmium coatings

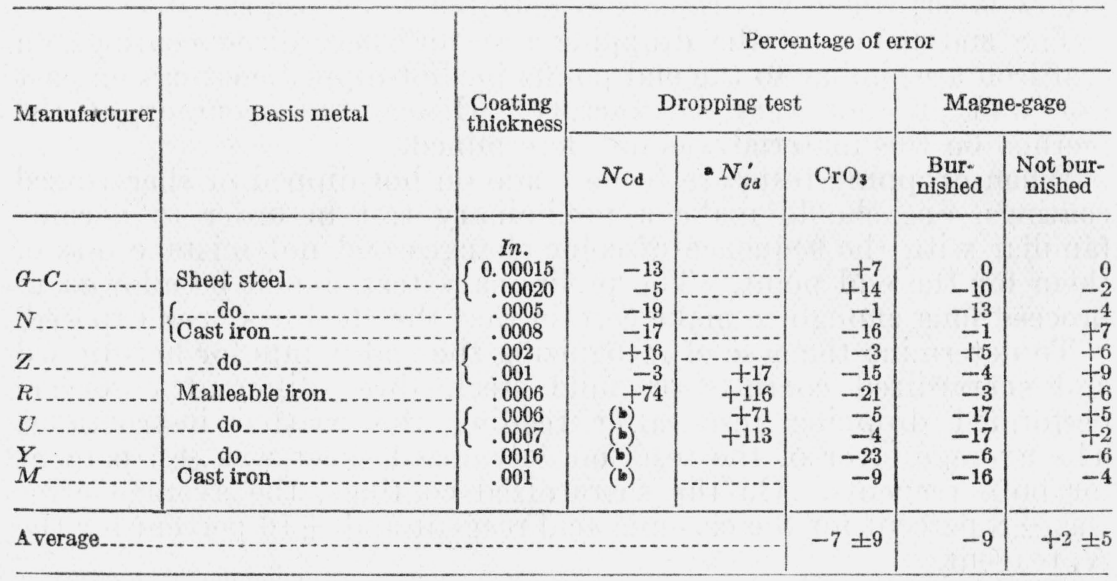

- Solution $\mathrm{NCd}_{\mathrm{C}}+3 \mathrm{q} / \mathrm{liter}$ of $\mathrm{K}_{\mathbf{3}} \mathrm{Fe}(\mathrm{CN})_{8}$.

- Unsatisfactory end point.

The percentage errors for the $N_{\mathbf{C d}}$ and $N_{\mathbf{C}^{\prime} \text { d }}$ solutions are subject to considerable uncertainty, because, as shown in table 3 , the factors for four proprietary cadmium deposits were not concordant. In testing cadmium coatings from various sources, it would be necessary to use some value that might be assumed to represent the average cadmium coating. Therefore, the average factors derived from table 3 were used. No such uncertainty is connected with the values for the chromic acid solution. 
(b) MAGNETIC MEASUREMENTS

The measurements with the Magne-gage were generally correct within \pm 15 percent. Burnishing the cadmium coating gave a somewhat low result, probably because the metal is so soft.

\section{MICROSCOPIC METHOD FOR ZINC AND CADMIUM COATINGS}

The microscopic method of measuring the thickness is not very satisfactory for zinc and cadmium coatings, because these metals are soft and flow when polished. Consequently, it is necessary to employ a special technique and to have considerable experience in order to obtain reliable results.

Several flat specimens, plated with coatings of known uniform thickness were measured microscopically in a laboratory ${ }^{8}$ experienced in such measurements. The results were accurate to \pm 5 percent. In the metallurgical laboratories of this Bureau this accuracy was approached by observers not previously experienced in measuring zinc coatings, only after a number of trials with different polishing procedures. This experience shows that great care is required to obtain reliable values on zinc and cadmium coatings.

\section{CONCLUSIONS}

\section{DROPPING TESTS}

The ammonium nitrate reagents have been found to operate satisfactorily with most types of zinc coatings on mild steel basis metals. Zinc-mercury coatings, however, do not yield a good end point, especially if they are deposited on rough surfaces. If the zinc-mercury coatings are tested with the modified reagent, containing potassium ferricyanide, a large positive error is obtained on coatings several ten-thousandths of an inch thick. The ferricyanide may increase somewhat the sharpness of end point with other coatings, but it is not essential. The ammonium nitrate reagents did not give satisfactory end points for hot-dipped or sherardized zinc coatings on cast iron.

The ammonium nitrate reagent is not satisfactory for cadmium coatings because it does not dissolve coatings from different sources at the same rate. Also the end point for some cadmium coatings on cast iron is indistinct.

The reagent containing $200 \mathrm{~g} /$ liter of chromic acid and $50 \mathrm{~g} / \mathrm{liter}$ of sulfuric acid gave a satisfactory end point with most coatings, including zinc-mercury coatings and cadmium plated on cast iron. The end points for hot-dipped and sherardized zinc coatings on cast iron were not so satisfactory, as the test had to be stopped in order to see the end point. In addition to giving better end points than the ammonium nitrate reagents with some coatings, the chromic acid reagent has the advantage that only one solution is required for testing electroplated, hot-dipped, and sherardized zinc coatings, and electroplated cadmium. Moreover, the application of the reagent is simplified, since the factors for the three kinds of zinc coatings are the same. On the other hand, four different ammonium nitrate solutions have been recommended for the dropping test, one for each type of coating,

8 New Jersey Zine Co., through the kindness of E. A. Anderson. 
as the original purpose was to develop solutions which had a factor equal to unity. This number of solutions could easily be reduced to three, by using the $N_{H}$ solution also for testing cadmium, but the number of solutions could not be further decreased without sacrificing either the accuracy or the sharpness of the end points. One advantage of the ammonium nitrate reagents over the chromic acid reagent is that the $N_{E}$ and $N_{H}$ solutions have factors with low temperature coefficients.

When satisfactory end points are obtained on coatings thicker than 0.0002 in. the dropping test gives results correct to within \pm 15 percent, if the basis metal is fairly smooth. However, if the coatings are deposited on rough surfaces or on cast iron, the measurements may be in error by \pm 20 percent. Therefore, if the dropping test is to be used in general testing for example, for compliance with specifications a tolerance of 20 percent should be allowed. When the dropping test is used for plant control, in which case the same type of coating would always be tested, results correct within \pm 10 percent can be obtained by making a correction for any systematic error.

\section{JET TEST}

The jet test was found to be less satisfactory than the dropping test as a general method for electroplated zinc coatings.

\section{MAGNETIC MEASUREMENTS}

The Magne-gage usually gave results correct within \pm 15 percent. Measurements of hot-dipped coatings were consistently about 10 percent low; hence for such coatings more accurate values can be obtained if the direct Magne-gage results are corrected by this amount. Burnishing improves the reproducibility and accuracy of measurements of zinc coatings plated on mild steel and of sherardized coatings. However, it is not necessary on hot-dipped coatings, and does not improve the accuracy of measurements of electroplated coatings on cast iron. The chief limitation of the Magne-gage, when applied to the commercial products, is that it does not accurately measure coatings thinner than 0.0008 in. that are deposited on cast iron.

\section{RECOMMENDATIONS}

1. The chromic acid reagent is recommended in preference to the ammonium nitrate reagents for testing zinc and cadmium coatings.

2. Even with the chromic acid reagent, a tolerance of -20 percent should be allowed on individual thickness measurements to take care of uncertainties in the end points, especially of coatings from different sources. This tolerance may be included directly in the minimum thicknesses specified.

3. The magnetic method is promising and certainly useful for plant control. Additional commercial experience will be required before it can be included in formal specifications.

4. The use of the microscopic method for umpire tests should be confined to laboratories having experience with these particular measurements.

\%. For many purposes the stripping method with hydrochloric acid and antimony trichloride is preferable as an umpire test. A piece 
with a total area of from 1 to $4 \mathrm{~cm}^{2}$ is cut from that portion of the article where the thinnest coating is suspected. It is carefully weighed (to $0.1 \mathrm{mg}$ ) and the portion of jts surface not to be stripped is coated with an acid-resistant lacquer, which is removed after the stripping and prior to reweighing. This method is usually reliable well within \pm 10 percent.

The author expresses his appreciation to W. Blum for his advice and guidance and acknowledges the assistance given by the Metallurgy Division of the Bureau and by W. A. Olson, who performed some of the tests. The author also thanks the following firms for furnishing most of the coated specimens used in the investigation:

Hanson-Van Winkle-Munning Co.; Grasselli Division, Dupont Co.; Udylite Process Co.; Meaker Co.; Thomas \& Betts Co.; Steel City Electric Co.; Crouse-Hinds Co.; Appleton Electric Co.; Jefferson Electric Co.; All-Steel Equipment Co.; The Rattan Manufacturing Co.; Benjamin Electric Mfg. Co.; Adalet Manufacturing Co.; Erie Malleable Iron Co.; General Electric Co.; and Bridgeport Switch Co.

Washington, June 7, 1939. 